UDC 616.314-0

LBC (P)56.6

\title{
THE USE OF ORAL FLUID TO DIAGNOSE PROBLEMS OF DENTAL IMPLANT OSSEOINTEGRATION ${ }^{1}$
}

\author{
Angelina O. Zekiy \\ Sechenov First Moscow Medical University, Moscow, Russian Federation \\ Anna S. Krylova \\ Volgograd State University, Volgograd, Russian Federation \\ Valery V. Novochadov \\ Volgograd State University, Volgograd, Russian Federation
}

\begin{abstract}
The study presents the results of defining some physico-chemical properties (viscosity and sliding friction coefficient) and four biochemical indices of oral fluid in 146 patients after installation of fixed dentures relying on intraosseous implants. On the basis of clinical examination, the prosthetic patients were divided in two clinical groups with different risk of poor or uncompleted adaptation to fixed dentures. Forty-eight peoples being practical health, made up a comparison group. As a result, we conclude, that the inclusion of used methods in the diagnostic complex to control osseointegration and adaptation of prosthetic patients allows more accurate predict the risk of late complications after dental implantation. These changes are in correlation with the classical signs of inflammatory processes in peri-implant tissues in the $\mathrm{X}$-ray examination, including determination of bone density around implants.

Key words: dental implantation, osseointegration, saliva, oral fluid, physico-chemical properties, cytokines, metalloproteinases.
\end{abstract}

УДК 616.314-0

ББК (Р)56.6

\section{ИСПОЛЬЗОВАНИЕ РОТОВОЙ ЖИДКОСТИ ДЛЯ ДИАГНОСТИКИ ПРОБЛЕМ ОСТЕОИНТЕГРАЦИИ В ДЕНТАЛЬНОЙ ИМПЛАНТОЛОГИИ ${ }^{1}$}

\author{
Ангелина Олеговна Зекий \\ Первый Московский медицинский университет им. И.М. Сеченова (Сеченовский университет), \\ г. Москва, Российская Федерация
}

\section{Анна Сергеевна Крылова}

Волгоградский государственный университет, г. Волгоград, Российская Федерация

Валерий Валерьевич Новочадов

Волгоградский государственный университет, г. Волгоград, Российская Федерация

Аннотация. В исследовании представлены результаты определения физико-химических свойств (рН, буферной емкости, вязкости, коэффициента трения скольжения) и четырех биохимических показателей) в ротовой жидкости 146 пациентов с несъемными протезами на имплантатах. На основании предварительного клинического обследования пациенты были распределены в две клинические группы с различным риском замедленной или неполной адаптации к зубным протезам. В качестве группы сравнения были обследованы 48 практически здоровых лиц. В результате исследования показано, что 
включение в диагностический комплекс контроля остеоинтеграции и адаптации пациентов к несъемным зубным протезам с опорой на внутрикостные имплантаты использованных методик позволяет более точно прогнозировать риск возникновения поздних осложнений дентальной имплантации. Эти изменения находятся во взаимосвязи с классическими признаками воспалительных процессов в периимплантационных тканях при анализе рентгенологического обследования, в том числе - при гистотопографическом определении плотности кости вокруг имплантатов.

Ключевые слова: дентальная имплантация, остеоинтеграция, слюна, ротовая жидкость, физико-химические свойства, цитокины, металлопротеиназы.

Исследование ротовой жидкости (РЖ) представляет собой неинвазивный инструмент не только для исследования состояния тканей зубочелюстной системы, самих слюнных желез, но и для получения информации о ряде системных изменений в организме [4; 8$]$. Хотя чаще при этом используются биохимические методики [2; 3; 6], несомненный интерес представляет оценка ее физико-химических свойств РЖ [1].

Цель работы - выявить возможности физико-химического и биохимического анализа ротовой жидкости для оценки риска нестабильной остеоинтеграции и развития поздних воспалительных осложнений дентальной имплантации.

Материалы и методы. В исследование было включено 146 пациентов с установленными несъемными конструкциями на имплантатах с продолжительностью эксплуатации 1-12 месяцев и 48 практически здоровых волонтеров в референтной группе. На основании клинического обследования пациенты были распределены в 2 клинические группы: первая из 102 человек с минимальным риском нестабильной остеоинтеграции и развития периимплантита; вторая из 44 человек с наличием такого риска.

Рентгенологические исследования выполнялись на аппарате Orthophos XG 3 DS (Sirona Dental Systems, Германия). При анализе полученных изображений учитывали характер вторичной адентии, высоту краевых отделов альвеолярных отростков, наличие пародонтальных карманов, состояние кости вокруг корней прилегающих зубов, а также состояние альвеолярных бухт верхнечелюстных пазух. Качественные исследования дополняли локальной денситометрией [5].

Сбор РЖ проводили натощак, в состоянии покоя. Для определения вязкости исполь- зовали метод микровизуализации [7]. Коэффициент трения скольжения $\mu$ был определен с помощью микродинамометра растяжения ДЭП1-1Д-0,1Р-1 (Пэт-Вес, Россия).

Концентрации ММР-8 и ТIMP-2 в РЖ определяли методом твердофазного иммуноферментного анализа с помощью наборов производства Quantikine ${ }^{\circledR}, \mathrm{R} \& \mathrm{D}$ Systems (CША), цитокинов - наборами Cloud-Clone Corp. (США), использовали микропланшетный ридер Bio-Rad (iMark, Japan).

Статистический анализ проводили с помощью пакета Statistica 10.0 (StatSoft Inc., США), использовали непараметрические критерии: для характеристики выборки - медиану, интервал между 1-м и 3-м квартилями (Ме [Q1 ․ Q3]), при сравнении выборок - критерий Манна-Уитни $(\mathrm{p}<0,01)$.

Результаты и их обсуждение. При локальной денситометрии получали характерные кривые распределения плотности кости, на которых были различимы перепады плотности внутри губчатого вещества (см. рисунок). Изменения средней плотности кости представлены в таблице 1.

Относительно более низкие значения плотности кости между имплантатом и окружающими зубами у пациентов второй клинической группы можно расценивать как потенциальные риски повышенной остеорезорбции и угрозы остеоинтеграции.

Значения вязкости РЖ через 2-4 месяца послепротезирования оказывались меньше значений в группе сравнения: в первой клинической группе - в 2,57 раза, во второй - в 1,64 раза. Период снижения в первой клинической группе период снижения захватывал сроки 5-8 месяцев после протезирования, во второй клинической группе в эти сроки значения вязкости были уже близки к нормальным (см. табл. 2).

Протезирование сопровождалось увеличением коэффициента трения скольжения: в 


\section{МАТЕРИАЛЫ КОНФЕРЕНЦИИ}

первой клинической группе в 1,38-1,46 раза от величины в группе сравнения на протяжении первых 8 месяцев наблюдения, во второй клинической группе - в 1,29 раза лишь на протяжении первых 4 месяцев.
У пациентов первой клинической группы в динамике наблюдения было относительно выше соотношение MMP-8/TIMP-2, что косвенно свидетельствовало о более высоком уровне остеорезорбции (см. табл. 3).

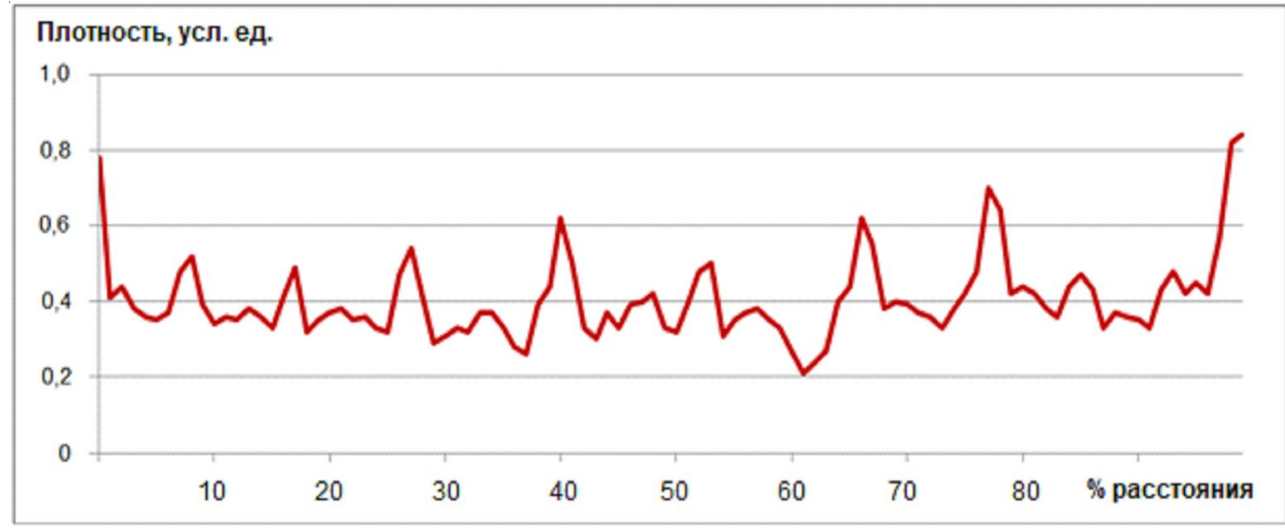

Рисунок. Кривая распределения плотности кости нижней челюсти при локальной денситометрии периимплантационной области от границы имплантата до корня соседнего зуба (расстояние выражено в \%)

Средняя плотность костной ткани в динамике эксплуатации несъемных конструкций на имплантатах (Me [Q1 - Q3], усл. ед.)

\begin{tabular}{|l|c|c|c|}
\hline \multicolumn{1}{|c|}{ Локализация } & Сроки & $\begin{array}{c}\text { Первая клиническая } \\
\text { группа }\end{array}$ & $\begin{array}{c}\text { Вторая клиническая } \\
\text { группа }\end{array}$ \\
\hline Промежуток «корень зу- & Начало & $0,38[0,29 \div 0,48]$ & $0,34[0,25 \div 0,39]$ \\
ба-имплантат» & $2-4$ мес. & $0,37[0,26 \div 0,45]$ & $0,28[0,23 \div 0,32]^{*}$ \\
& $5-8$ мес. & $0,35[0,28 \div 0,45]$ & $0,26[0,22 \div 0,30]^{*}$ \\
& $9-12$ мес. & $0,40[0,31 \div 0,52]$ & $0,29[0,24 \div 0,34] *$ \\
\hline Компактная пластинка & Начало & $0,61[0,50 \div 0,68]$ & $0,54[0,46 \div 0,62]$ \\
челюсти & $2-4$ мес. & $0,58[0,49 \div 0,66]$ & $0,55[0,43 \div 0,63]$ \\
& $5-8$ мес. & $0,59[0,52 \div 0,67]$ & $0,60[0,49 \div 0,69]$ \\
& 9-12 мес. & $0,58[0,50 \div 0,65]$ & $0,57[0,47 \div 0,65]$ \\
\hline
\end{tabular}

Примечание. * - p < 0,01 между группами по критерию Манна - Уитни.

Таблиияа 2

Физико-химические характеристики РЖ пациентов в динамике эксплуатации несьемных конструкций на имплантатах (Me [Q1 Q3])

\begin{tabular}{|c|c|c|}
\hline Сроки эксплуатации & Первая клиническая группа & Вторая клиническая группа \\
\hline \multicolumn{2}{|c|}{ Вязкость: в группе сравнения $181[139 \div 218]$ мПа·с } \\
\hline $2-4$ мес. & $264[210 \div 307]$ & $73[44 \div 107]$ \\
$5-8$ мес. & $252[197 \div 291]$ & $112[52 \div 0,136]^{*}$ \\
$9-12$ мес. & $248[191 \div 278]$ & $158[94 \div 239]$ \\
\hline Коэффициент трения скольжения: в группе сравнения $0,18[0,14 \div 0,21]$ \\
\hline $2-4$ мес. & $0,33[0,28 \div 0,35]$ & $0,33[0,28 \div 0,39]^{*}$ \\
$5-8$ мес. & $0,32[0,28 \div 0,34]$ & $0,35[0,29 \div 0,41]$ \\
9-12 мес. & $0,31[0,27 \div 0,34]$ & $0,23[0,18 \div 0,28]$ \\
\hline
\end{tabular}

Примечание. * - ${ }^{*}<0,01$ с группой сравнения по критерию Манна - Уитни. 


\section{Маркеры воспаления и остеорезорбции в РЖ пациентов в динамике эксплуатации несъемных конструкций на имплантатах (Me [Q1 Q3])}

\begin{tabular}{|c|c|c|}
\hline Сроки эксплуатации & Первая клиническая группа & Вторая клиническая группа \\
\hline \multicolumn{3}{|c|}{ MMP-8/TIMP-2: в группе сравнения $6,63[4,15 \div 9,33]$} \\
\hline $2-4$ мес. & $7,51[5,24 \div 10,40]$ & $2,63[1,99 \div 4,73]$ \\
\hline 5-8 мес. & $8,23[6,05 \div 10,96]$ & $2,58[2,02 \div 4,66]$ \\
\hline $9-12$ мес. & $9,53[7,30 \div 12,08]$ & $2,81[2,21 \div 5,10]$ \\
\hline \multicolumn{3}{|c|}{ IL-1 $\beta /$ MIP-1 $\alpha:$ в группе сравнения $-28,5[18,6 \div 40,7]$} \\
\hline $2-4$ мec. & $8,69[6,20 \div 11,36]$ & $32,5[21,5 \div 47,7]$ \\
\hline 5-8 мес. & $8,43[6,01 \div 11,05]$ & $41,1[28,3 \div 60,2]$ \\
\hline $9-12$ мес. & $7,04[4,88 \div 9,91]$ & $61,5[39,6 \div 84,8]$ \\
\hline
\end{tabular}

Примечание. ${ }^{*}-\mathrm{p}<0,01$ с группой сравнения по критерию Манна - Уитни.

В те же сроки у таких пациентов было относительно ниже соотношение IL-1 $/$ MIP$1 \alpha$, что было расценено как более вероятное развитие местных воспалительных явлений и риск периимплантита

Заключение. Включение в диагностический комплекс контроля остеоинтеграции и адаптации пациентов к несъемным зубным протезам с опорой на внутрикостные имплантаты таких методик, как исследование физико-химических (вязкость и коэффициент трения скольжения) и биохимических (определение коэффициентов MMP-8/TIMP-2 и IL-1 $\beta$ / MIP-1 $\alpha$ ) свойств РЖ позволяет более точно прогнозировать риск возникновения поздних осложнений дентальной имплантации. Эти изменения находятся во взаимосвязи с классическими признаками воспалительных процессов в периимплантационных тканях при анализе рентгенологического обследования, в том числе - при гистотопографическом определении плотности кости вокруг имплантатов.

\section{ПРИМЕЧАНИЕ}

${ }^{1}$ Рекомендовано к публикации оргкомитетом Всероссийской научной конференции с международным участием «ИССЛЕДОВАНИЕ ЖИВЫХ СИСТЕМ В ПОСТГЕНОМНУЮ ЭРУ» (Волгоград, 1518 мая 2018 г.)

\section{СПИСОК ЛИТЕРАТУРЫ}

1. Зекий, А. О. Физико-химическая и биохимическая характеристика смешанной слюны на различ- ных сроках после дентальной имплантации // Вестник Волгоградского государственного университета. Серия 11: Естественные науки. - 2015. - № 4. - С. 22-29.

2. Матриксные металлопротеиназы и воспалительные цитокины в ротовой жидкости больных хроническим генерализованным пародонтитом с различными конструкционными материалами реставраций зубов и зубных рядов / Е. А. Соловых, Т. Б. Караогланова, Н. Е. Кушлинский, О.О.Янушевич // Клиническая лабораторная диагностика. - 2013. - № 10. - С. 18-21.

3. Шемонаев, В. И. Сравнительная информативность морфологических, рентгенологических и биомеханических критериев остеоинтеграции в эксперименте / В. И. Шемонаев, В. В. Новочадов, А. Ю. Алексеенко // Тихоокеанский медицинский журнал. - 2014. - № 3. - С. 22-25.

4. Bhardwaj, S. K. Comparative volumetric and clinical evaluation of peri-implant sulcular fluid and gingival crevicular fluid / S. K. Bhardwaj, M. L. Prabhuji // J. Periodontal Implant Sci. - 2013. - Vol. 43, № 5. P. 233-242.

5. Evaluation of survival and success rates of dental implants reported in longitudinal studies with a follow-up period of at least 10 years: a systematic review / V. Moraschini, L. A. Poubel, V. F. Ferreira, S. Barboza Edos // Int. J. Oral Maxillofac. Surg. 2015. - Vol. 44, №3. - P. 377-388.

6. Kajale, A. M. Interleukin-1в level in periimplant crevicular fluid and its correlation with the clinical and radiographic parameters / A. M. Kajale, D. S. Mehta // J. Indian Soc. Periodontol. - 2014. Vol. 18, № 2. - P. 220-225.

7. Novochadov, V. V. Production technology and physicochemical properties of composition containing surfactant proteins / V. V. Novochadov, P. A. Krylov // Eur. J. Mol. Biotech. - 2016. - №2. - P. 77-84.

8. Targeted salivary biomarkers for discrimination of periodontal health and disease(s) / J. L. Ebersole, R. Nagarajan, D. Akers, C. S. Miller// Front. Cell Infect. Microbiol. -2015. - Vol. 5. - P. 62. 


\section{Information about the Authors}

Angelina O. Zekiy, Candidate of Sciences (Medicine), Associate Professor, Department of Orthopedic Dentistry, Sechenov First Moscow Medical University, Trubetzkaya St., 8, Bd. 2, 119991 Moscow, Russian Federation, angelinaolegovna@gmail.com.

Anna S. Krylova, Post-Graduate Student, Institute of Natural Sciences, Volgograd State University, Prosp. Universitetskiy, 100, 400062 Volgograd, Russian Federation, biobio@volsu.ru.

Valery V. Novochadov, Doctor of Medical Sciences, Professor, Director of the Institute of Natural Sciences, Volgograd State University, Prosp. Universitetskiy, 100, 400062 Volgograd, Russian Federation, novochadov.valeriy@volsu.ru.

\section{Информация об авторах}

Ангелина Олеговна Зекий, кандидат медицинских наук, доцент кафедры ортопедической стоматологии Первый Московский медицинский университет им. И.М. Сеченова (Сеченовский университет), ул. Трубецкая, 8, стр. 2, 119991 г. Москва, Российская Федерация, angelinaolegovna@gmail.com.

Анна Сергеевна Крылова, аспирант института естественных наук, Волгоградский государственный университет, просп. Университетский, 100, 400062 г. Волгоград, Российская Федерация, biobio@volsu.ru.

Валерий Валерьевич Новочадов, доктор медицинских наук, профессор, директор института естественных наук, Волгоградский государственный университет, просп. Университетский, 100, 400062 г. Волгоград, Российская Федерация, novochadov.valeriy@volsu.ru. 